\title{
"New approach" as Health Canada seeks conditional licences for drugs, new pediatric office
}

A longer version was published at www.cmaj.ca on Mar. 2, 2005.

Health Minister Ujjal Dosanjh's vision for a revamped drug approval system in Canada includes conditional licensing for some drugs and the creation of a

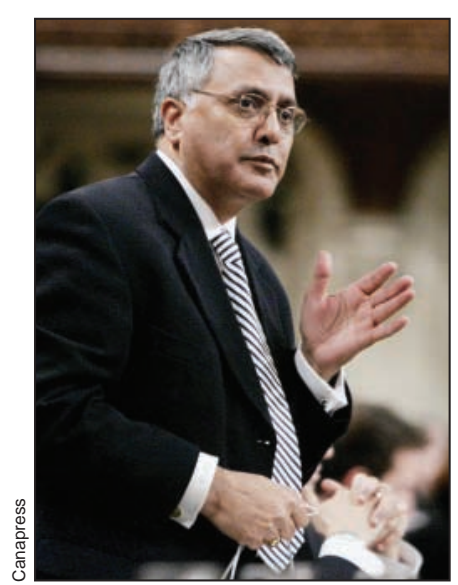

Health Minister Ujjal Dosanjh has set an activist agenda. new pediatric office to assess prescription drugs for children.

These plans will require not only legislative change, but a wholesale shift in the department's culture, Dosanjh told CMAJ in a Feb. 28 interview.

"This is a whole new culture we want to create and a whole new approach that we want to create around our drug approval and postmarket surveillance," he said. "I would like to do it soon. I know this is a complex and difficult issue. It is not going to [happen] overnight."

The Feb. 23 budget (see page 863 ) sets aside $\$ 170$ million over 5 years for drug safety, including postmarket surveillance of adverse events. The department still has available a portion of the $\$ 190$ million set aside in the 2003 budget for speeding up drug review, so a large proportion of the $\$ 170$ million will go to postmarket surveillance, Dosanjh said.

Health Canada needs legislative authority to grant conditional drug approvals or licences to pharmaceutical companies, Dosanjh said. Enhanced surveillance, adverse drug reporting $\$$ and further clinical trials might 吉 "perhaps be attached to those approvals."

Since being sworn in last July, Dosanjh has set an activist agenda, including pushing for reform of the drug approval system. He has called for an open and transparent approach both from pharmaceutical companies and within his department, long criticized by media and public interest groups for being secretive and protective of the pharmaceutical industry. The department won the Canadian Association of Journalists' 2004 "Code of Secrecy" award.

Health Canada officials have long cited commercial confidentiality or proprietary interests to justify their refusal to release information about deliberations to approve or withdraw drugs. Most recently, journalists have asked for documents and details of the department's deliberations surrounding rofecoxib (Vioxx) and amphetamine salts (Adderall XR).

"I always begin with the assumption that people have a right to know. That anybody who wants to keep certain issues secret or confidential ... has to justify why that information should not be available to the public," said Dosanjh.

"The drug companies and the Health Canada regulator has to jump through those hoops, as far as I am concerned," he added. "I am challenging the department on that. I have challenged them on that for some time."

In mid-February Dosanjh told journalists - to the surprise of the pharmaceutical industry - that he would create a permanent advisory panel to solicit and review public input into both pre-approval and postmarketing surveillance of drugs. The panel, which he now refers to as a "safety board," will consist of experts from within Health Canada and outside. Members of the board will be asked to disclose potential conflicts of interests.

The minister would not lay out a timeline for the creation of the board and for other proposed changes to the drug ap- proval system, such as mandatory reporting by physicians and pharmaceutical companies on adverse drug events. At press time, he was writing to Parliament's Standing Committee on Health to ask it to take up these issues and recommend ways to put the safety board and other changes into place.

One of those is the creation of a pediatric office. "As you know, some of these drugs are never ... tested with respect to children," Dosanjh said. "We want to make sure we put in place an office that deals with those kinds of issues."

He did not know if the pediatric office would or should be given the power - which may require amendments to the Food and Drugs Act - to require pediatric trials of all new drugs potentially used to treat children. That is one of the issues the parliamentary committee will address. The committee will decide whether to hear the issue during this session of Parliament or next fall.

Health Canada regulators, based on input through the safety board, would decide what drugs require conditional licensing, and what drugs available to treat children might require more clinical trials, Dosanjh said.

"One size fits all isn't the approach that ever really helps," he said.

If Dosanjh is able to open up the drug approval process, he hopes Canada will not need an independent agency to review submissions.

"When we're moving toward more openness, transparency and accountability, if at some point it appears to those of us who are dealing with these issues that an independent agency would be what is required, that's what we would have," he said. - Laura Eggertson, CMAJ 